\title{
EDUARDO MALLEA: ESCRITURA, MITO Y SOLEMNIDAD
}

Nora Pasternac*

Eduardo Mallea (1903-1983) fue uno de los escritores argentinos más apreciados durante las décadas en las que ejerció su actividad. A partir de su primer libro, Cuentos para una inglesa desesperada, de 1926, hasta la publicación de sus memorias o papeles privados al final de su vida, fue considerado por la mayoría de los críticos con gran respeto y admiración. ${ }^{1}$ Desde el comienzo de su carrera ejerció una especie de magisterio moral, filosófico, estético e ideológico muy marcados. Durante años, estuvo a cargo de la sección cultural del prestigioso e influyente diario La Nación, órgano de la oligarquía liberal culta. Participó como fundador e impul-

* Centro de Lenguas, ITAM.

${ }^{1}$ La obra de Eduardo Mallea es vastísima y su habilidad para escoger títulos eufónicos y evocadores, legendaria. He aquí algunos: Nocturno europeo (novela, 1935), La ciudad junto al río inmóvil (nueve novelas cortas, 1936), Historia de una pasión argentina (ensayo, 1937), Fiesta en noviembre (novela, 1938), La bahía del silencio (novela, 1940), Todo verdor perecerá (novela, 1941), El sayal y la púrpura (ensayos, 1946), Los enemigos del alma (novela, 1950), La vida blanca (ensayo, 1961). Su producción abarca cerca de cuarenta volúmenes. 
NORA PASTERNAC

sor de la célebre revista Sur (1931-1987) junto a Victoria Ocampo (1890-1979), con quien estuvo unido por un tiempo en una relación más que profesional. Como personaje central en la revista influyó en sus orientaciones, en la elección de muchos de los autores que se publicaron en ella y constituyó un polo en cierto modo opuesto a la figura de Jorge Luis Borges en la medida en que sus opciones estéticas fueron completamente disímiles.

En este caso me propongo seguir la trayectoria de Eduardo Mallea ${ }^{2}$ en los primeros años de $S u r^{3}$ para sacar a la luz algunos de los antecedentes que subyacen a su pensamiento, antecedentes que raras veces fueron evocados, y que aclaran con una luz especial la ideología "liberal" $^{\prime 4}$ atribuida a los colaboradores de la revista y también a una buena parte de sus lectores.

${ }^{2}$ Sobre él se puede consultar a Myron I. Lichtblau, El arte estilistico de Eduardo Mallea, 1967, Buenos Aires, Juan Goyanarte y a Attilio Dabini, "Intelectualismo y existencialismo: Eduardo Mallea", La historia de la literatura argentina, $\mathrm{t}$. Iv: Los proyectos de la vanguardia, 1980-6, Buenos Aires, Centro Editor de América Latina, p. 433-56. El presente trabajo es un desprendimiento de una tesis consagrada a la revista Sur.

${ }^{3}$ He escogido deliberadamente los primeros 14 años de la revista (1931-45), pues al terminarse la Segunda Guerra Mundial, la comunicación de América con Europa vuelve a establecerse y en Sur empiezan a aparecer poco a poco otros textos que distribuyen las relaciones y las influencias de los escritores de manera diferente; imperceptiblemente, el lugar de Mallea va a ser revisado aunque nunca totalmente cuestionado.

${ }^{4}$ Por razones obvias no puedo entrar en una discusión sobre el concepto de liberalismo. Sabemos que la etiqueta esconde una variedad muy amplia de posibilidades: libertades individuales y públicas, emancipación y autorrealización del hombre, valorización de la democracia social, del sufragio universal y del pluralismo político; pero también existen versiones aristocráticas, reivindicadas por élites restringidas que, en el mejor de los casos, aspiran a infiltrar en el pueblo las "pasiones democráticas" más "desinteresadas" y "puras". 
El primer texto que Mallea publica en la revista se llama "Sumersión", 5 y formará parte, junto con otras historias, del libro La ciudad junto al río inmóvil(1936). Cuenta las vicisitudes de un hombre, Avesquín que, al enviudar de una esposa muy querida, se embarca para Buenos Aires desde Europa. Su profesión consiste en pintar frescos con la imagen de la Acrópolis en los muros de bares, cantinas, cafés o restaurantes. Pero en estas tierras "no consigue colocar ninguna Acrópolis."

Durante los primeros días de su estancia se siente bien, pero al cabo de dos semanas la ciudad se le aparece, como si él fuera un vidente, con su verdadero rostro: "grandiosidad helada".

En realidad, la historia sólo cuenta los vagabundeos de Avesquín, su encuentro (que es un desencuentro) con algunos personajes de la ciudad, su desesperación por no poder descifrar a la extraña urbe, sus pensamientos, acompañado por un narrador, que insistentemente retoma el punto de vista de Avesquín.

Al final, Avesquín, buscando huir, llega al puerto y espera las embarcaciones que lo sacarán de Buenos Aires, "páramo inmenso".

En el número $9{ }^{6}$ se publica el cuento "Suerte de Jacobo Uber" que, como el anterior, formará parte de La ciudad junto al río inmóvil. En este relato vemos avanzar hacia el suicidio final a Jacobo, "afectado de una extraña dolencia del alma" desde su infancia, enfermedad cuyas causas no se explican y que en realidad parece un caso de depresión grave.

${ }^{5}$ Eduardo Mallea, Sur, 3, verano de 1932, p. 86-133. Citaré de esta manera breve a la revista cada vez que sea preciso. Como resumen de su historia, tenemos lo siguiente: en 1931 aparecieron cuatro números, a partir del verano; en 1932, salieron sólo dos números, verano y otoño. La publicación fue interrumpida desde julio de 1934 hasta julio de 1935. A partir de allí Sur apareció mensualmente hasta diciembre de 1953; bimensualmente desde 1953 hasta 1972. Finalmente, se suspendió la publicación regular y empezaron a aparecer números especiales o monográficos hasta fines de la década de los 80. Muchos de estos números recogían artículos anteriormente publicados por la revista.

${ }^{6}$ Sur, julio de 1934 , p. 69-112. 
En el número 11, ${ }^{7}$ se publica "Momento Vitae" en el que un hombre camina por una ciudad solo, pero rodeado por una multitud que aumenta su soledad. Realiza varias diligencias relacionadas con su trabajo en un diario, almuerza en un restaurante, camina, cena, vuelve a caminar. Entra en un café donde se aburre y vuelve a su casa para dormir. Durante ese tiempo piensa en sí mismo, en su carrera de escritor, en el año que está por terminar y en el mundo que lo rodea.

En el número $33,{ }^{8}$ el relato "Noche" propone una introducción que un narrador en primera persona enuncia. Se trata, una vez más, de un hombre solo que camina por la ciudad de Buenos Aires de noche. Sentado en el banco de una plazoleta, riene el recuerdo de "una imagen". A partir de allí se intercala el largo relato de un hombre que vela desde hace varios días a su mujer moribunda, en el campo, a dos horas de automóvil del pueblo más cercano. La mujer acaba de dar a luz y está probablemente (pues no se aclara en ningún momento) sufriendo de fiebre puerperal o de una grave infección. El marido la cuida y recuerda el pasado, sin grandes avatares, de ambos. Afuera, en el campo, llueve interminablemente y la cosecha se arruina. El hombre apenas puede mantenerse despierto. En un acceso de desesperación sale a

74 caminar en plena lluvia por el campo fangoso e inundado. Al volver a la casa, la mujer parece haber muerto, pero el hombre finge creer que ella duerme. Él cae agotado y se duerme en el suelo al lado de la cama de la enferma. Todo este relato lleva una tipografía diferente de la introducción y del corto final en el cual el narrador se levanta y camina nuevamente por la ciudad.

En el número $70,{ }^{9}$ se publica un relato llamado "Un bien pensante" en el cual Mallea presenta a un joven literato que asiste a la fiesta de una especie de "Madame Verdurin" local, donde conoce a un "bien pensante" que expone sus ideas sobre el mundo y la crisis.

Este personaje, pagado de sí mismo, pontificador y reivindicador de la caridad, reacciona con asco y desconsideración cuando choca con

${ }^{7}$ Sur, agosto de 1935, p. 40-7.

${ }^{8}$ Sur, junio de 1937, p. 33-52.

${ }^{9}$ Sur, julio de 1940 , p. 40-8. 
un ciego, al abandonar la fiesta en compañía del narrador, contradiciendo así su prédica piadosa anterior.

En los números 99 y $100,{ }^{10}$ aparece un largo cuento, "Juego", en el que un personaje llamado Landor cuenta en primera persona su vida. Niño malvado y cruel, se escapa de su familia al llegar a la adolescencia. Deambula por la ciudad, se une a unos vagabundos y vive con ellos un largo tiempo en trenes, ciudades de provincia y puebluchos anónimos. En medio de esas aventuras, se separa del grupo y se une a uno de esos miserables vagabundos que dice ser pianista. Juntos emprenden una serie de intentos de estafa con variada suerte hasta un final trágico: el suicidio del pianista.

La historia está contada con un lenguaje que pretende ser popular y argótico y llaman la atención la "perversidad" del protagonista, su rencor y desprecio constantes hacia el mundo y las personas, y la extraña persistencia de la unión de los dos personajes (el narrador y el pianista) en algo que Mallea parece querer presentar como una relación sadomasoquista entre los dos hombres.

Reducidos a su mínima expresión, despojados del estilo laborioso y de la retórica malleana estos argumentos causan una impresión de modernidad y renovación notables. Parecen, así resumidos, pertenecer a esas corrientes, que algunos críticos llaman aliteratura o antinovela, y a las cuales se suele adscribir a Proust, a Robert Musil y su Hombre sin cualidades, al Ulises de Joyce, etc. Novelas que rompen con la tradición decimonónica de contar historias en las que las peripecias eran más importantes que el lenguaje.

Sin embargo, a diferencia de esas manifestaciones modernas de disolución de la narratividad, los libros de Mallea están perfectamente "anclados" en una posición ideológica que impregna todo lo que escribió y lo separa de los grandes autores citados por una insistencia declarativa que hace que su modo de llevar a cabo esta renovación difiera enormente de ellos e incluso quede neutralizada por las intervenciones moralizantes. Mallea es expositivo y discursivo, o sus voces narrativas lo son.

${ }^{10}$ Sur, diciembre de 1942, p. 7-26 y Sur, enero de 1943, p. 45-78. 
NORA PASTERNAC

Hay en él una voluntad demostrativa que no se esconde, y por lo tanto sobrecarga a sus relatos con un intelectualismo excesivo.

Antes de analizar algunos elementos formales y de construcción de la literatura de Mallea, recordemos algunos desarrollos que tienen fundamental importancia para estos textos que encontramos en Sur. La referencia principal es Historia de una pasión argentina. Allí, Mallea expone su conocida teoría sobre una Argentina "visible" y otra "invisible". La primera concentra todas las negatividades y la segunda todo lo positivo.

La Argentina visible está fundamentalmente en Buenos Aires, en la mayor parte de sus habitantes, de cultura asimilada rápidamente, pero superficial. La Argentina visible ha heredado de las corrientes inmigratorias la búsqueda de la riqueza y de la comodidad. Y eso es un gran error pues:

La vida es un empleo del hombre en la tragedia; un empleo del hombre en cierta guerra que da respiro pero no tregua larga [...] Estos hombres que vinieron gritando su aspiración de riquezas, no lo olvidemos, venían de terribles anarquías morales, de pobrezas indecibles, de órdenes europeos ligados a su crisis y su disolución. Con su ansiedad liberatoria, ¿qué podían traer a otra tierra? ¿Creéis que principios en qué basar una nacionalidad, un mundo armónicos? No. El orden no comienza en una evasión hacia la comodidad, sino en una conciencia de cierto sacrificio para cierto fin. ${ }^{11}$

Además, la Argentina visible ha sustituido "el vivir por el representar"; no piensa, sólo actúa. En consecuencia, todos viven para la exterioridad:"Su género es el discurso; su apoteosis, el banquete; su seducción más inquietante, la publicidad. ${ }^{12}$

${ }^{11}$ Eduardo Mallea, Historia de una pasión argentina, 1942, 2a., Buenos Aires, Espasa Calpe, p. 68.

${ }^{12}$ Ibidem, p. 71. 
El supuesto refinamiento de la sociedad es una ficción, el gesto es lo que cuenta, el silencio puede ser un simple gesto (el silencio tiene una significación diferente en la Argentina invisible) que evita el compromiso y nada más, el miedo al ridículo es llevado hasta el extremo, etc. Los hombres y mujeres que constituyen esta Argentina visible invaden, por definición, todos los espacios más respetables y degradan al verdadero saber y a la genuina espiritualidad.

Espiritualidad que Mallea relaciona directamente con la herencia de la España católica (aunque él declara no tener la fe; adhiere a la espiritualidad mística de España) y, por extensión, al resto de la Europa católica:

...el hecho supremo y heroico: la gesta de Hernán Cortés, Juana de Arco, Chartres. Tal es la bendición de nuestra herencia de España, más que nuestra deuda con el genio latino. [...] "Si este hombre argentino visible no fuera adventicio y tuviera raíz, su raíz sería lo español. Entonces creería en los valores extremos o absolutos, que son en último término los que he querido decir al hablar de fines. 'El español -ha dicho alguna vez un sagaz español- cree en los valores absolutos o deja de creer totalmente. Para nosotros se ha hecho el dilema de Dostoiewsky: o el Valor absoluto o la nada absoluta'. Pero para nuestro hombre visible, lo absoluto no existía, claro está. ${ }^{13}$

A todos los defectos del argentino visible hay que agregarle el hecho de que desdeña estas tradiciones, menosprecia la "tierra auténtica" del país, carece de poder creador y de capacidad científica. Para Mallea, todo esto constituye una causa consternante de la decadencia del país.

Después de la enumeración de estas catástrofes, Mallea expresa un violento sentimiento de odio y unas ansias de aniquilación del prójimo que asombran por su virulencia:

${ }^{13}$ Ibid., p. 75 y 78. 
NORA PASTERNAC

He odiado a esta gente culpablemente falsa, habría querido acosarlos, golpearlos, reducirlos al silencio, limpiar la atmósfera de su presencia. [...] Contaminado. Así me sentía. Y odiaba a esos deformadores, a esos traidores, a esos burgueses dormidos en el lecho de cierta venal incuria [...] en la calle, en los clubes, en los salones literarios, en las tertulias de 'cejialtos' y 'cejialtas' iba a encontrarme una vez más con esta gente, hombres desvirtuados, desnaturalizados, islas anodinas [...] Erraba por la ciudad hasta el puerto. Al amparo de la soledad nocturna, en la oscura costa, la cara ofrecida a la brisa del río de aguas casi inertes, me sentía, por un momento rescatado. $\mathrm{He}$ aquí el agua libre, la noche libre, el espacio libre, los astros libres-el universo. ${ }^{14}$

En estas palabras y en esta temática reencontramos exactamente los desarrollos de los cuentos, sólo que aquí algunos elementos de condena están desarrollados más claramente y son la expresión conservadora del miedo a las nuevas capas de inmigrantes extranjeros que se iban integrando con mayor o menor eficacia y armonía al nuevo país, y que

78 asustaban a la misma oligarquía liberal propiciadora de la llegada masiva de esas corrientes inmigratorias.

En cambio, el país invisible es portador de todo tipo de virtudes y excelencias. En primer lugar, está situado en el interior del país (las ciudades grandes como Córdoba o Rosario parecen estar excluidas), en "ciudades blancas" o "caseríos elementales", pero fundamentalmente tierra adentro. Hay que aclarar que estas "ciudades blancas" parecen totalmente imaginadas por Mallea si pensamos que toda la arquitectura de los pueblos del interior de la Argentina corresponde a las pautas de construcción más o menos "estéticas" de esos mismos inmigrantes que los poblaron y fundaron, fundamentalmente italianos y españoles pobres, que obviamente no pudieron repetir el esplendor arquitectónico de sus respectivos países de origen en la nueva tierra a la que trataron de

${ }^{14}$ Ibid., p. 76-7. 
adaptarse con las dificultades habituales que suponen las inmigraciones y los exilios.

El hombre argentino invisible tiene una serie de atributos que se reflejan en los adjetivos que Mallea usa para definirlo: tranquilo, colonial, no deformado por la "bárbara venida de una invasión sin genio original, confusa, caótica", no contaminado por la ambición, taciturno (y aquí el silencio es positivo), altivo, apegado a la tierra, sin cálculo, "naturalmente pródigo", sacrificado, imperturbable, en permanente "exaltación severa de la vida". 15

La dicotomía que presenta Mallea tiene una amplia tradición. En primer lugar, parece invertir los términos de Sarmiento: civilización y barbarie, pues ahora la "barbarie" aparentemente circula por las calles de la ciudad y adora el "progreso" y el "bienestar", que en este modelo adquieren la carga negativa, al contrario de lo que representaban para Sarmiento. Aunque, en realidad, las oposiciones de Mallea corresponden también a dos autores franceses que él apreciaba: Péguy y Maurras.

Charles Péguy (1873-1914), escritor de orígenes modestos (siempre se refirió con orgullo a su ascendencia campesina) pudo seguir estudios como becario y entrar, en 1894, en la "Ecole Normale Supérieure" donde tuvo como maestros a Joseph Bédier, Romain Rolland y sobre todo Henri Bergson. Militó en la izquierda socialista y a favor de los dreyfusistas durante el famoso proceso. En 1900 se separó de sus antiguos compañeros de lucha, cuyo anticlericalismo y antimilitarismo desaprobaba, para fundar la revista Cahiers de la Quinzaine, y abordar en ella todos los problemas políticos contemporáneos junto con colaboradores como Romain Rolland y Julien Benda. Sus artículos revelan una evolución curiosa: alarmado por la "amenaza de una invasión alemana" va a relacionar su mística socialista con una mística de

15 Todos estos términos están tomados del capítulo IV: "El país invisible. La tierra auténtica, la tierra profunda y su hombre. La fisonomía moral del argentino profundo. La exaltación severa de la vida. La lucha espiritual. El trabajo sin ensueño. El descontento creador." Eduardo Mallea, Historia..., p. 81-94. 
NORA PASTERNAC

la patria francesa a la cual percibe como una figura privilegiada de la "Ciudad de Dios", puesto que en ese tiempo volvió fervientemente a la fe católica. A partir de allí, se opone al "mundo moderno", a las acciones de los políticos, a la moral congelada de los "bien pensantes", y propugna una vuelta al "interior de la raza" para encontrar la misión de "heroísmo y santidad de la tierra carnal". ${ }^{16}$ Como vemos, este pensamiento influyó, con algunas modificaciones, en Eduardo Mallea que frecuentemente cita o menciona a Péguy con admiración. A estos núcleos ideológicos, hay que agregar una gran influencia del estilo de la poesía y de la prosa de Péguy sobre Mallea: vastas letanías, con estructuras incansablemente repetitivas, lentitud solemne y formas de plegaria con tono profético.

Por su parte, Charles Maurras (1862-1952) es uno de los más importantes ideólogos de la derecha. Estuvo contra Dreyfuss en el "caso" y fundó el movimiento de extrema derecha "La Acción Francesa" (19081944) de la cual fue el principal animador. A partir de ese movimiento defendió el "nacionalismo integral", síntesis de tradicionalismo y de nacionalismo (Mis ideas políticas, 1937) y ejerció un influjo considerable sobre la parte más conservadora de la burguesía francesa. Apoyó a Mussolini, a Franco y luego al Mariscal Pétain; por este último episodio en que se convirtió en "colaboracionista", se lo condenó a reclusión perpetua en 1945, aunque fue liberado, muy enfermo, poco antes de su muerte. ${ }^{17}$

Durante los años treinta ambos autores están en consonancia con las preocupaciones de Mallea. De Péguy saca la contraposición entre el país "de antes", en el que se vivía sobria y patriarcalmente y la Francia "de ahora" deformada por el "bajo interés". Maurras, por su parte, establece una oposición que se parece tanto a las dicotomías de Péguy como a la "Argentina visible" opuesta a la "invisible" de Mallea: para

${ }^{16}$ Sobre Péguy: Bernard Guyon, Pégzy, 1973, París, Hatier.

${ }^{17}$ Sobre Maurice Barrès se puede consultar de Zeev Sternhell, Maurice Barrès et le nationalisme français, 1972, París, Armand Colin y del mismo La Droite révolutionnaire (1885-1914), les origines françaises du fascisme, 1978, París, Seuil. 
Maurras existe el "país legal" y el "país real". Por la misma época, el filósofo Alain, maestro de toda la generación de pensadores de los años treinta, bien conocido por Mallea, establece oposiciones semejantes: la ciudad es el territorio de maniobras donde triunfan los "importantes", y donde se han establecido las avenidas del Poder y del Dinero. Por el contrario la provincia es el depósito de las rudas virtudes de la franqueza, la frugalidad y la vigilancia.

De estas notas y descripciones muy someras del pensamiento de esos autores se percibe que los ensayos y la narrativa de Mallea son la ilustración obsesiva e insistente de esas ideas, que constituyen su genealogía ideológica, ideas apoyadas por un estilo repetitivo que tiene grandes semejanzas con el de Péguy.

Veamos algunos ejemplos extraídos de las narraciones que hemos resumido más arriba:

\begin{abstract}
Ah, en aquella ciudad el agua moraba en napas remotas, grandes moles de piedra hueca interceptaban el sol, los hombres tenían entre sí contactos inconfesables. Estos hombres se ocultaban para vivir y uno los sorprendía, amantes crudos, huyendo de los hoteles amueblados con una mano en la cara, huyendo de los parques donde su breve presencia era también subrepticia. Estos hombres olvidaban el destino de sus manos, las tornaban incapaces de asir, de acariciar a la ventura, naturalmente, como la carne desarrolla y satisface su hambre. ${ }^{18}$
\end{abstract}

En este párrafo ya están planteados todos los decorados, los motivos, los personajes y los conflictos. Reiteradamente la ciudad será "amarga", "asfixiante", "Babilonia"; sus calles serán "callejuelas" lúgubres, los bulevares, "ásperos"; los árboles, "desollados".

En cuanto a la gente, "extraña gente", sin comunicación, casi siempre en multitudes que giran "desintegradas", "ni un solo núcleo de humana diversión"; o bien "figuras opulentas", "gentes que venían [a

${ }^{18}$ Eduardo Mallea, Sur, 3, verano de 1932, art. cit., p. 91. 
NORA PASTERNAC

la iglesia] luego, a injuriar [...] con su hipocresía y su falsa beatitud". Cuando algún personaje aislado emerge de la masa su figura es despreciable, deforme o repugnante: "la dama equívoca", "damas de charla fácil y práctica", "caras estigmatizadas", "un mozo escuálido se le acercó con indolencia", "una mujer enana, agitada y colérica", "un hombre tambaleante [...] vomitó su alcohol en el cordón de la acera", "esa masa de desechos le parecía asquerosa", las "negociaciones miserables", sus "caracteres siniestros.

Si la metrópolis tiene "aire cocotesco" y además "en el fondo no había más que frialdad como en el rostro que la mueca ilumina", algunos personajes , como el Avesquín de "Sumersión", por ejemplo, sueñan

con las provincias de este país, con la pampa, las viñas y los Andes, que había visto en vagas oleografías. Su nariz reseca por los vientos y las tierras antiguas reclamaba esos olores intensos y sustanciosos, mojados como la uva reciente en las acequias. Soñaba, a través de lecturas imprecisas, con el relámpago de los campos infinitos y llovidos, con la planicie, de río a río, de población en población, donde el grito humano perdura largamente; donde la sensualidad del hombre obedece al sol, cesa con la hora del ruego, al atardecer, hora de cansancio y de tregua, hora en que el horizonte abandona su presa, devora las leguas planas, se acerca, se confunde con la noche y rodea a cada ser con la mansedumbre del aire circundante.[...] 'Barro, barro', gritaba su espíritu, ávido, mientras se libraba de la opresión de la urbe. La piedra protestaba bajo sus pies. Al llegar a la proximidad de las luces del barrio sórdido sonreía, respiraba. Ya sabía él lo que era esta metrópoli [...]) Tierra de prostitución, de falsos símbolos. Tierra húmeda, nueva y maravillosa, vencida por el oro del sacrificio ganadero; vencida por el capital de un cúmulo de miserables generaciones arribadas de regiones extrañas a la comodidad y a la ambición, a la adulteración de lo expectable. ${ }^{19}$

${ }^{19}$ Ibidem, p.102-3. 
Estas contraposiciones se acentúan por algunos efectos de la construcción de los textos de Mallea en los que las ideas o la necesidad de explicar se encarnan en un punto de vista (de un narrador o de un personaje), una focalización monológica y olímpica que ahoga toda posibilidad de matizar las condenas o de darle la palabra a los "condenados". Los réprobos son totalmente, y sin salvación, réprobos y los puros, totalmente puros. Estas características no son "representadas" a través de acciones o peripecias, sino que un narrador nos presenta por medio de comentarios y opiniones, en un sistema descriptivo, casi sin diálogos, lo que debemos entender o interpretar de la evolución de los personajes. Naturalmente, hay que suponer que el autor, vidente e iluminado, está del buen lado, puesto que es él quien pone en escena estos conflictos y "ve" por encima de todos.

Es difícil saber cómo hace el narrador para saber cuáles son las actitudes "buenas" y cuáles las malas. El mismo silencio puede ser laconismo condenable, debido a la brutalidad o a la ignorancia, o, por el contrario, silencio sufriente y altivo de un "argentino invisible". Si alguien no nos lo dice, no podríamos decidirlo a través de la trama o de los diálogos. Los personajes sólo se manifiestan a través de una meditación intelectual que se declara "angustiosa" y no tenemos otro punto de vista para entrar en ellos.

Las soluciones para el conflicto argentino, reflejadas literariamente en los cuentos, están bien resumidas por los subtítulos del último capítulo, "La exaltación severa de la vida", en Historia de una pasión argentina:

Regreso. Despojarse de todo. Las tinieblas gobernadas. E1 camino de Damasco. El áspero y duro destierro. La mejoración de sí. La exaltación severa, norma de la creación del hombre. Ir más allá de uno mismo para alcanzar las últimas fronteras de lo humano. Los territorios espirituales.

Todo este sistema deslumbró, en su momento, a los contemporáneos del autor. Emir Rodríguez Monegal define muy bien la posición 
NORA PASTERNAC

de Mallea en Sur y nos da luces suplementarias sobre la crítica literaria que acompañó al autor, describiendo al mismo tiempo el sistema cerrado y reverente que se produjo alrededor suyo:

Porque Mallea [...] concitó desde el primer momento el aplauso y el entusiasmo y la glosa reiterada de sus primeros lectores. Había en su denuncia de la Argentina visible [...] y en su exaltación de la Argentina invisible; [...] en su dicotomía elocuente y henchida de las dos Argentinas, no sólo la fuerza suasoria de la retórica y la pasión con que estaba investida esta retórica, sino una esperanza: la esperanza de que esa Argentina invisible asumiera pronto la representación de la otra ante el mundo, desterrando y obliterando, la imagen vana, codiciosa y servil que ahora ofrecía [...] Y toda la intelligentsia argentina, la que Sur congregaba en sus páginas inauguradas desde 1931, aplaudió sin descanso a Mallea. Lo aplaudió por éste y otros libros que reiteraban (en ficción, en ensayo) la misma tesis; lo aplaudió en copiosos artículos de glosa que firmaban Canal Feijoo o José Bianco, Ana M. Berry, Amado Alonso, Francisco Ayala, Guillermo de Torre, Luis Emilio Soto. Como el Ariel de Rodó [...] el libro de Mallea (y sus secuelas novelísticas) promovió una adhesión general apasionada de sus coetáneos, y el joven maestro (tiene 34 años cuando lo publica) ocupó pronto el sitio de uno de los intocables de su generación. Sucesivas ediciones, incluso una enorme en la colección Austral, con un prólogo en que Francisco Romero (recogiendo dócilmente un par de alusiones del propio Mallea) descubre la semejanza entre la Historia de una pasión argentina y el (sí, es cierto) Discurso del método; sucesivas consagraciones en el extranjero que culminan con la edición norteamericana de La bahía del silencio, la más legible trasposición en clave narrativa de esa pasión; sucesivos cargos que le permiten (como el de director del suplemento literario de La Nación) el ejercicio de una suave dictadura sobre las letras argentinas; sucesivos honores visi- 
bles e invisibles colman al joven, lo visten de importancia, proyectan su mensaje y lo convierten en el primer escritor de su generación. ${ }^{20}$

En los últimos años de la década del cuarenta y en toda la del cincuenta, la figura de Mallea ya no es tan reverenciada. Incluso en Sur aparecen algunos sintomas de desencanto. Por ejemplo, un artículo de Santiago Montserrat en el que las críticas al teórico de las dos Argentinas se adelantan ya a las que se harán durante los años posteriores. ${ }^{21}$ Sin embargo, eso es excepcional. Hasta el fin, Sur seguirá considerando con devoción a Eduardo Mallea. Así, en el número del cincuentenario, un artículo dedicado a él, sigue celebrando sus "grandes constelaciones simbólicas"; particularmente las de Historia de una pasión argentina y las novelas que continúan ilustrando la dicotomía lo visible y lo invisible. ${ }^{22}$

Los ataques más fuertes vendrán del grupo de jóvenes críticos que se reúnen en la revista Contorno que, entre otras tomas de partido, se definen y definen su ejercicio de la literatura contra Sur y particularmente contra Mallea. ${ }^{23}$

Y, por supuesto, también en esos años se desarrollará el análisis de todo lo que opone a Mallea al otro polo de Sur: Jorge Luis Borges. Pero esto rebasa los límites del presente trabajo y debemos deternos aquí.

${ }^{20}$ Emir Rodríguez Monegal, Narradores de esta América, 1970, Montevideo, Alfa, p. 250-1.

${ }^{21}$ Santiago Montserrat, "Eduardo Mallea y la Argentina profunda", Sur, 123, enero de 1945, p. 72-83.

${ }^{22}$ Cristina Piña, "Sentido y función de 'La ciudad junto al río inmóvil' dentro de la obra de Mallea", Sur, 348, enero-junio de 1981, p. 49-54.

${ }^{23}$ Véase León Rozitchner, "Comunicación y servidumbre: Mallea", en Contorno (Antología de textos de la revista) seleccionados y presentados por Carlos Mangone y Jorge A. Warley, 1981, Buenos Aires, Centro Editor de América Latina, p. 107-32; David Viñas, "Sur: Sobrevivencia y reemplazos del escritor. Mallea", en De Sarmiento a Cortázar, 1973, Buenos Aires, Siglo XX, p. 83-9. 